\title{
A Novel Approach for Sericin-Conjugated Silver Nanoparticle Synthesis and Their Potential as Microbicide Candidates
}

\author{
Xiaowen $\mathrm{Lv}^{1}$, Huanru Wang ${ }^{2}$, Airong $\mathrm{Su}^{3}$, and Ying $\mathrm{Chu}^{4 *}$ \\ ${ }^{1}$ Department of Pediatrics, Affiliated Hangzhou First People's Hospital, Zhejiang University School of Medicine, Hangzhou 310006, P.R. China \\ ${ }^{2}$ Center for Public Health Research, Medical School, Nanjing University, Nanjing 210098, P.R. China \\ ${ }^{3}$ Central Laboratory, The Second Affiliated Hospital of Nanjing Medical University, Nanjing 210029, P.R. China \\ ${ }^{4}$ Central Laboratory, The Affiliated Wujin People's Hospital of Jiangsu University, Changzhou 213002, P.R. China
}

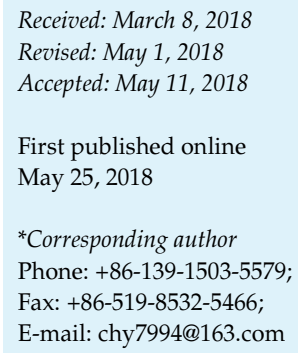

Silver nanoparticles have been widely applied for biomedical areas owing to their potent antiviral and antibacterial activities. Synthesis of silver nanoparticles using biomacromolecules is more efficient, environment-friendly, and cost-saving compared with the traditional approach. In this paper, a novel approach was developed to establish a reaction system with $\mathrm{Ag}^{+}-\mathrm{BH} 4-$-sericin to synthesize silver nanoparticles conjugated to sericin (AgNPs-Sericin). Sericin could be as a good dispersant and stabilizing agent, which is able to modify nanoscaled AgNPs, the average diameter of which was only $3.78 \pm 1.14 \mathrm{~nm}$ prepared in a $0.3 \mathrm{mg} / \mathrm{ml}$ sericin solution. The characterizations of the AgNPs-Sericin were determined by FTIR, thermogravimetry, and XRD analyses. The results showed that the synthesized AgNPs conjugated with sericin as organic phase. Via SAED and XRD analysis, we showed that these AgNPs formed polycrystalline powder with a face-centered cubic structure of bulk metals. Moreover, we investigated the antiviral and antibacterial activities of AgNPs-Sericin, and the results showed that AgNPs-Sericin exhibited potent anti-HIV-1 activity against CCR5-tropic and CXCR4-tropic strains, but no significant cytotoxicity was found toward human genital epithelial cells compared with free silver ions, which are accepted as a commonly used potent antimicrobial agent. Moreover, its antibacterial activity was determined via flow cytometry. The results showed that AgNPs-Sericin could suppress gram-negative (E.coli) and grampositive (S. aureus) bacteria, but more was potent for the gram-negative one. We concluded that our AgNPs-Sericin could be a potential candidate as a microbicide or antimicrobial agent to prevent sexually transmitted infections.

Keywords: Silver nanoparticles, sericin, anti-HIV, antibacterial, microbicide

\section{Introduction}

Bacterial and viral infections present a high risk for people's healthcare. Although many antibiotics or other antimicrobial agents are widely used in clinical or nonclinical healthcare, antibiotic or drug resistance has gradually become one of the most significant threats [1]. Among severe infection diseases, HIV-1 infection has become one of the greatest threats to human health. Since the advent of the AIDS pandemic, efforts have been directed to the search of viral inhibitory agents. Unprotected heterosexual intercourse is the most common mode of HIV-1 transmission worldwide $[2,3]$. With no preventive vaccine, people are looking for alternative approaches to prevent the sexual transmission of HIV, such as tropical microbicides. Microbicides are any compounds, molecules, or agents that can prevent people from sexual transmitted diseaseassociated pathogens, not only viruses, such as HIV and herpes, but also bacterial infections [4, 5]. Moreover, bacterial infection and resistance are the main difficult clinical conundrum [6]. Thus, searching for novel antimicrobial agents, antibiotics, and antiseptics has become urgent and 
is accelerating for the prevention of microbial infections.

Nanotechnology and nanomedicine are widely developing disciplines to advance the properties of certain nanomaterials for medicine or clinical application [7]. Nanomaterials have played a vital role in pharmaceuticals, and these materials can be candidates as carriers to deliver drugs, as well as broad-spectrum antimicrobial/antiviral/antitumor agents [8]. Silver is a noble metal and widely used in many trades. In ancient China and other countries, people used this metal to forge food containers to control microbe contamination. Many lines of evidence have verified that silver has the ability to kill several pathogenic microorganisms [9-11]. Over the past few decade, silver nanoparticles (AgNPs) have been widely used in different types of applications [12]. Several manuscripts reported that AgNPs exhibited effective antibacterial/antifungal activity [13-15]. Elechiguerra et al. [16] reported that AgNPs were confirmed to be a promising anti-HIV-1 material via interaction with HIV glycoprotein, gp120. Baram-Pinto et al. [17] also showed that AgNPs that are capped with mercaptoethane sulfonate can target HSV-1 and compete with the binding sites to cellular heparin sulfate through their sulfonate end groups, which leads to the blockage of viral entry into the cell and the prevention of subsequent infection through this kind of binding [17]. However, cytotoxicity is the main problem and obstacle for their wide application in medicine. AgNPs will release free silver ions and cause mitochondrial dysfunction and induction of ROS, which in turn set off DNA damage and chromosomal aberrations [18]. For reducing the cytotoxicity of AgNPs, surface modification may be a good short cut to solve this problem through using some biomacromolecules or polymers (e.g., starch or protein). Sericin is a type of protein created by Bombyx mori (silkworms) in the production of silk. Its good biocompatibility and biodegradability are experimentally proved, and it exhibits safety in foodstuff, medicine, cosmetics, and so forth [19]. In this paper, we employed sericin as a surface modifier and disperser in AgNP synthesis to prepare novel sericin-modified AgNPs, and herein we discuss their antiHIV-1 and antibacterial potentials.

\section{Materials and Methods}

\section{Cell Lines, Virus, and Bacteria}

VK2/E6E7 cells (human ectocervix epithelial cells) were obtained from ATCC and cultured in keratinocyte-serum free medium (Gibco, 17005-042) with $0.1 \mathrm{ng} / \mathrm{ml}$ human recombinant EGF, $0.05 \mathrm{mg} / \mathrm{ml}$ bovine pituitary extract, and $0.4 \mathrm{mM}$ calcium chloride. Ghost R5X4 cells were from the AIDS Research and Reference
Reagent Program, National Institute of Health and maintained in DMEM supplemented with $10 \%$ FBS.

HIV-1 Env pseudotype viruses were prepared by cotansfecting 293T cells with the Env expression plasmid and Env-deficient backbone plasmid as previously described [20]. Plasmid pNL4-3 Env- and pcDNA3.1-Env (JR-FL and HxB2) were gifted by Prof. Zhang Linqi from Tsinghua University, China. The HIV-1 pseudovirus stock solution was harvested $48 \mathrm{~h}$ after transfection, filtered by $0.45 \mu \mathrm{m}$ filter (Millipore, US), and stored at $-80^{\circ} \mathrm{C}$.

The $50 \%$ tissue culture infectious dose $\left(\mathrm{TCID}_{50}\right)$ of each strain was identified in Ghost R5X4 cells. Serial 5-fold dilutions of the pseudovirus were prepared and mixed with $10^{4}$ freshly trypsinized cells in 96-well plates. The total volume was maintained to $100 \mu \mathrm{l}$ containing $5 \mu \mathrm{g} / \mathrm{ml}$ DEAE-dextran. The plates were incubated at $37^{\circ} \mathrm{C}$ in a humidified $5 \% \mathrm{CO}_{2}$ air environment. After $48 \mathrm{~h}$, the medium was removed and $100 \mu$ lof Glo lysis buffer (Promega, USA) was added. Then, $50 \mu$ of cell lysis solution was mixed well with the same volume of Bright-Glo luciferase substrate in 96-well white solid plates (Corning, USA). The luminescence was measured using a Glo-Max luminometer (Promega, USA), and the TCID $_{50}$ was calculated as described previously [21].

Staphylococcus aureus ATCC 25923 and Escherichia coli ATCC 25922 were from ATCC. The pure cultures of bacteria were cultured on nutrient broth medium.

\section{Preparation of AgNPs-Sericin}

Silk sericin protein, silver nitrate, and sodium borohydride were purchased from Sigma-Aldrich (USA). Briefly, a series of silver nitrate $(0.8 \mathrm{mM})$ solution with different concentrations of sericin protein were prepared. The solutions were then gently stirred and titrated with $0.8 \mathrm{mM}$ sodium borohydride solution at room temperature. The molar ratio of $\mathrm{Ag}^{+}: \mathrm{BH}^{-}$was maintained at 1:1. The mixture was stirred constantly overnight, and the final AgNP solution was transparent and yellow to brown. AgNPs were isolated using Millipore ultrafiltration tubes ( $15 \mathrm{ml}, 30 \mathrm{kD})$. The precipitates were harvested and washed with deionized water twice. The samples were stored at $4^{\circ} \mathrm{C}$ for further research.

\section{Characterizations of AgNPs-Sericin}

The fresh silver collosol was directly measured with a UV-Vis spectrophotometer (TECAN, Infinate M200), scanning from 300 to $700 \mathrm{~nm}$ with $0.5 \mathrm{~nm}$ as data interval for evaluating the formation and yields of AgNPs-Sericin. For transmission electron microscopy (TEM) detection, the collosol was deposited onto 200-mesh copper grids coated with carbon film and dried. TEM was conducted with a JEOL JEM-2100 microscope with selected area electron diffraction (SAED) operating at $200 \mathrm{keV}$ beam energy. The sizes of nanoparticles were measured from TEM photos via ImageJ software, and the size distribution was analyzed using Origin 8.0 software.

The chemical structure of AgNPs-Sericin was analyzed by X-ray diffractometry (XRD), Fourier-transform infrared spectroscopy (FTIR), and thermogravimetry (TG). XRD analysis was performed 
on a D/max-rA diffractometer (Rigaku, Japan) with $\mathrm{Cu} \mathrm{K \alpha}$ radiation. The samples were scanned from $10^{\circ}$ to $60^{\circ}$ with a speed of $6 \% \mathrm{~min}$. For FTIR analysis, the powders were mixed with potassium bromide in the mass ratio of 1:20. Scans were taken using a Thermo Nicolet C NEXUS870 Fourier transform infrared spectrometer scanning in the range of 4,000 to $400 \mathrm{~cm}^{-1}$. TG was carried out with a heating rate of $20^{\circ} \mathrm{C} / \mathrm{min}$. A Pyris $1 \mathrm{DSC} / 0.2 \mathrm{uw}$ thermogravimetric analyzer was employed. The measurement range was from room temperature to $900^{\circ} \mathrm{C}$.

\section{In Vitro Cytotoxicity Assay}

The in vitro cytotoxicity of AgNPs against VK2 and Ghost R5X4 cells was determined using the CCK-8 kit (Dojindo, Japan) in accordance with the manufacturer's protocol. Briefly, $1 \times 10^{4}$ VK2 or Ghost R5X4 cells per well were seeded into 96-well plates. After $24 \mathrm{~h}$ culture, the medium was replaced by a series of diluted AgNPs-Sericin-containing medium and the plates were incubated for another $48 \mathrm{~h}$. The medium was discarded and the wells were washed twice with PBS. Following these steps, $100 \mu \mathrm{l}$ of fresh medium and $10 \mu \mathrm{l}$ of CCK- 8 work solution were added into each well. The plates were incubated at $37^{\circ} \mathrm{C}$ for $4 \mathrm{~h}$ and $\mathrm{OD}$ values were read at $450 \mathrm{~nm}$ by a TECAN Infinate M200 plate reader (TECAN, Switzerland). All results were subtracted by the OD values of medium only with CCK-8. The percentages of living cell in the wells were calculated using the formula described below. All the experiments were triplicated.

Live cells $\%=\left[\left(\mathrm{OD}_{\text {cells with drugs }}\right) /\left(\mathrm{OD}_{\text {cells with no drugs }}\right)\right] \times 100 \%$

\section{In Vitro Anti-HIV-1 Assay}

Ghost R5X4 cells were seeded into 96-well plates at a concentration of $10^{4}$ per well and incubated for $24 \mathrm{~h}$. Then, the medium was replaced with $150 \mu \mathrm{l}$ of DEAE-dextran $(5 \mu \mathrm{g} / \mathrm{ml})$ containing DMEM. A high-titer HIV-1 stock solution was diluted to $8,000 \mathrm{TCID}_{50} / \mathrm{ml}$ and mixed with the same volume of AgNP solution and $50 \mu \mathrm{l}$ of the mixture was added into a 96-well plate. The final titer of virions was $200 \mathrm{TCID}_{50}$ per well. The level of viral infection was quantified by measurement of the relative luciferase units (RLU) using the GloMax-96 Microplate Luminometer (Promega, USA) that were directly proportional to the amount of virus inputs. All the experiments were triplicated.

\section{In Vitro Antibacterial Assay}

The in vitro antibacterial assay was as described by Pan et al. [22], but modified. S. aureus and E. coli cells were harvested in the exponential phase and collected by centrifugation $(10,000 \times g$, $5 \mathrm{~min}, 4^{\circ} \mathrm{C}$ ). The cell pellets were washed and then suspended with PBS. The cell concentration was adjusted to approximately $10^{6} / \mathrm{ml}$. To investigate the bacterial growth number after exposure to different concentrations of AgNPs-Sericin, various concentrations of the nanoparticles (final concentrations $0,6.25 \mu \mathrm{M}, 12.5 \mu \mathrm{M}$, $25 \mu \mathrm{M}, 50 \mu \mathrm{M}, 0.1 \mathrm{mM}$, and $0.2 \mathrm{mM}$ ) were mixed with $\sim 10^{6}$ bacterial cells in nutrient broth medium. After mixing, the bacterial cells were kept at $37^{\circ} \mathrm{C}$ for $6 \mathrm{~h}$ with agitation at $200 \mathrm{rpm}$.
Bacterial cell numbers within these samples were evaluated by flow cytometric counting with SYBR Green I staining. All samples were diluted 100 times, and $500 \mu$ dilutions were stained with SYBR Green I (1× working concentration) (Life Technologies, USA) for $15 \mathrm{~min}$ in the dark. The bacterial cell counting assay was performed on a BD Accuri C6 flow cytometer. One hundred microliter samples were measured and SYBR Green positive cells were gated and counted directly.

\section{In Vitro Bactericidal Test}

The effects of the nanoparticles on the bacterial live/dead ratio were measured via two-color fluorescence flow cytometric analysis. Ten million bacterial cells were treated with AgNPs-Sericin (final concentration $0.1 \mathrm{mM}$ ) for $15 \mathrm{~min}$ at room temperature. The samples were diluted 100 times and then stained with SYBR Green I (1× working concentration) and PI $(10 \mu \mathrm{g} / \mathrm{ml})$ (Life Technologies, USA) for 15 min protecting from light. Cell viability was analyzed by flow cytometry. Live cells should be SYBR Green-positive, but PI-negative. When damaged or dead, cells would show double-positive staining.

\section{Results}

\section{Characterization of AgNPs-Sericin}

We hypothesized that sericin from silkworm cocoon can be used as a dispersing and stabilizing agent for AgNP formation owing to its protein characterization. Firstly, we considered the effect of the sericin concentration in the reaction system on AgNP synthesis and yields. Through the maximum absorption wavelength $\left(\lambda_{\max }\right)$ and the peak width at half maximum (PWHM) measurement, we could determine the yield and homogeneity of the AgNPs. Nanoparticles with a smaller size have a lower value of $\lambda_{\max }$, and a lower value of PWHM represents better particle homogeneity. OD values at $\lambda_{\max }$ represent synthesized nanoparticle yields. As shown in Fig. 1, AgNPs would aggregate to form macroscopic insolubles in the absence of sericin. Once sericin was included in reaction solutions, the collosol would change yellow, and then to brown. When the concentration of sericin reached $0.3 \mathrm{mg} / \mathrm{ml}$, the PWHM value was relatively low, and the OD value reached the maximum, indicating the excellent homogeneity and the maximum AgNP yield. However, higher sericin concentrations used might lead to formation of larger size of AgNPsSericin particles due to the larger $\lambda_{\max }$ values and lower OD values. It was concluded that $0.3 \mathrm{mg} / \mathrm{ml}$ sericin was the optimal concentration for AgNP synthesis for its best dispersivity and particle-size controlling.

The TEM images of a region of AgNPs synthesized with sericin are shown in Fig. 2. The majority of AgNPs were nearly spherical. It was confirmed by SAED that these 


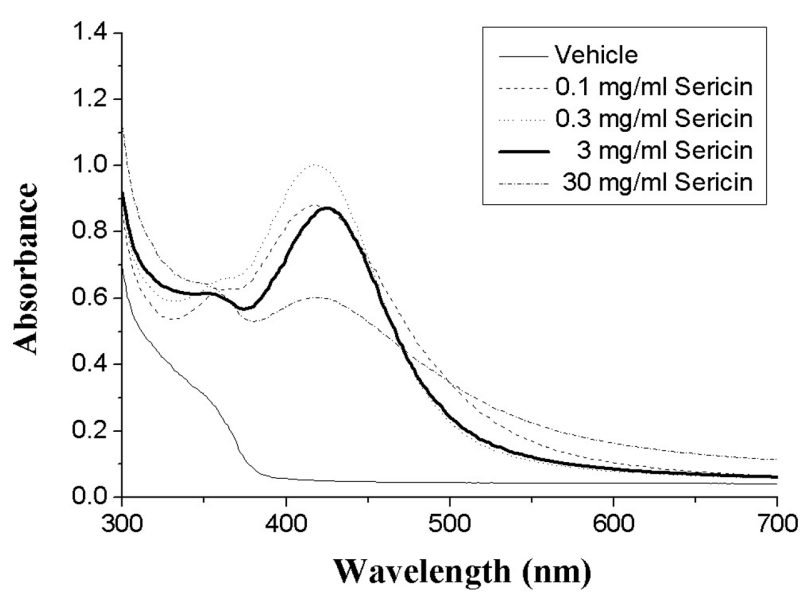

Fig. 1. UV-Vis spectra of AgNPs-Sericin solutions synthesized under different concentrations of sericin.

The $\lambda_{\max }$ and peak width at half maximum were measured to determine the yield and homogeneity of the silver nanoparticles.

nanoscale particles formed a polycrystalline powder with a face-centered cubic structure of bulk metals, viewed as polycrystalline rings on the electron diffraction pattern that were made up of many diffraction spots (Fig. 2E). This result was also verified by the XRD results described below. It was revealed that the AgNPs were composed of some small crystal nuclei, and, without sericin in solution, the particles congregated with each other and the sizes of these particles were approximately $30-50 \mathrm{~nm}$. The bad dispersivity of these AgNPs caused them to be unsuitable for wide use. Surprisingly, not only could silk sericin disperse the particles, but it was also able to control the particle diameter. The particles in Fig. 2B reached to $3.78 \pm 1.14 \mathrm{~nm}$, which was much smaller than that in Fig. 2A. However, with increased concentration of sericin, the nanoparticle sizes expanded (Figs. 2C and 2D), demonstrating that $0.3 \mathrm{mg} / \mathrm{ml}$ sericin concentration was the best for small-size AgNP preparation. Fig. 2F shows the size distribution for AgNPs generated from $0.3 \mathrm{mg} / \mathrm{ml}$ sericin solution.

FTIR spectra of AgNPs with different contents of sericin or pure sericin powder are shown in Fig. 3A. When there was no sericin in the AgNP synthesis process, no characteristic absorption peak could be detected because silver atoms have no covalent bonds to connect with each other. However, AgNPs synthesized from sericin solution
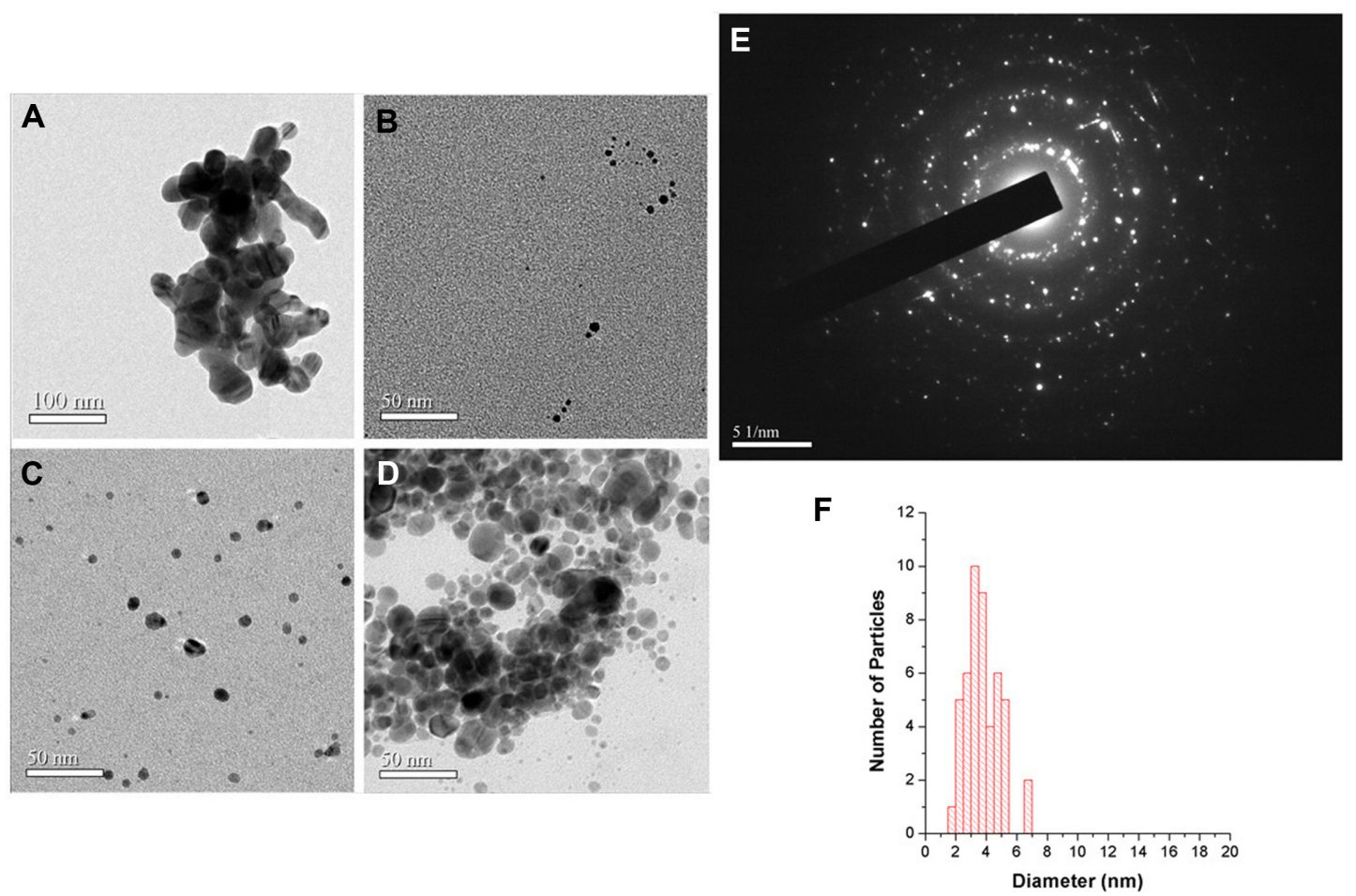

Fig. 2. TEM images showing the size and shape of silver nanoparticles prepared with different sericin concentrations.

(A) $0 \mathrm{mg} / \mathrm{ml}$ sericin; (B) $0.3 \mathrm{mg} / \mathrm{ml}$ sericin; (C) $3 \mathrm{mg} / \mathrm{ml}$ sericin; (D) $30 \mathrm{mg} / \mathrm{ml}$ sericin. (E) SAED pattern of AgNPs-Sericin synthesized in $0.3 \mathrm{mg} / \mathrm{ml}$ sericin solution. (F) Size distribution of AgNPs generated in $0.3 \mathrm{mg} / \mathrm{ml}$ sericin solution. 

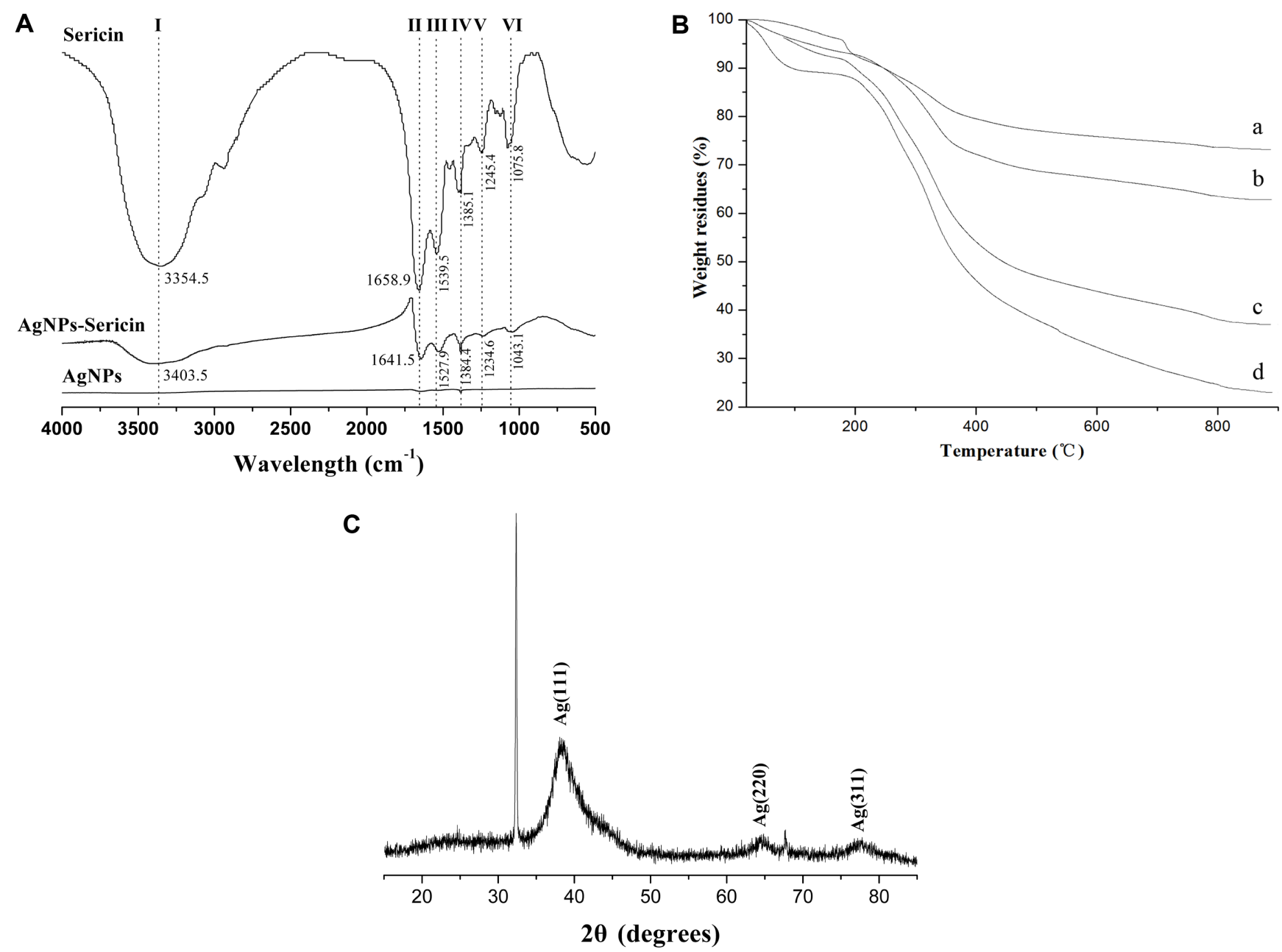

Fig. 3. Characterizations of AgNPs-Sericin.

(A) FTIR spectra of silver nanoparticles synthesized with or without sericin $(0.3 \mathrm{mg} / \mathrm{ml})$ and pure sericin powder. (B) Thermogravimetric curves of silver nanoparticles produced in solutions with different sericin concentration: (a) $0.3 \mathrm{~g} / \mathrm{l}$; (b) $3 \mathrm{~g} / \mathrm{l}$; (c) $30 \mathrm{~g} / \mathrm{l}$; (d) sericin powder. (C) XRD pattern of silver nanoparticles formed in $0.3 \mathrm{mg} / \mathrm{ml}$ sericin solution.

had some specific absorption peaks that were identical with sericin, demonstrating that silver atoms could integrate with sericin molecules with a certain mode and form metalprotein complexes. It was also found that the intensity of peaks would be stronger along with sericin content increase, proving that a higher concentration of sericin in solution would cause higher content in formed AgNPs. In Fig. 3A, Curve I, the absorption band at $3,345.5 \mathrm{~cm}^{-1}$ was $\mathrm{O}-\mathrm{H}$, which existed in either $\mathrm{H}_{2} \mathrm{O}$ or $-\mathrm{OH}$ from amino acid residues. The peaks in Curve II, III, and V at 1,658.9, 1,539.5, and $1,245.4 \mathrm{~cm}^{-1}$ were mainly caused by the random coil structure. The absorption bands at $1,658.9$ and $1,539.5 \mathrm{~cm}^{-1}$ represent $\mathrm{C}=\mathrm{O}$ groups and $\mathrm{C}-\mathrm{N}$ or $\mathrm{N}-\mathrm{H}$ that might be composed in peptide bonds and aliphatic amino acids in sericin molecules, respectively.
The sericin synthesized in AgNPs-Sericin complexes was further measured by TG. As shown in Fig. 3B, sericin decomposed quickly at $300^{\circ} \mathrm{C}$ to $400^{\circ} \mathrm{C}$ and almost disappeared at $900^{\circ} \mathrm{C}$. Obviously, these AgNP materials contained a part of the organic phase, the content of which increased when higher sericin concentration was used in the reaction solution. Curve a, corresponding to silver nanoparticles produced from $0.3 \mathrm{mg} / \mathrm{ml}$ sericin solution, illustrated that the percent of weight of organic phase (sericin) was approximately $22.4 \%$.

The XRD pattern of AgNPs prepared in solution with $0.3 \mathrm{mg} / \mathrm{ml}$ sericin is shown in Fig. 3C. The major XRD peaks could be well assigned to (111), (220), and (311) crystallographic planes of face-centered cubic silver crystals (JCPDS file No. 01-071-4613). 

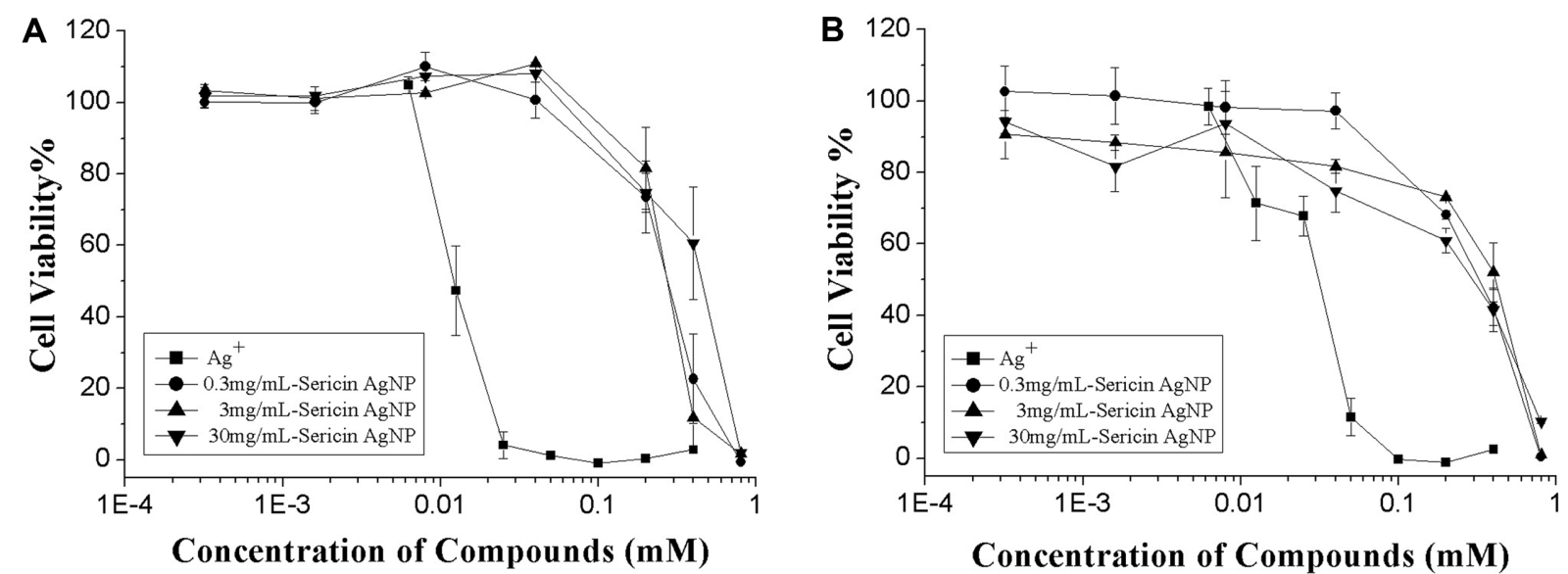

Fig. 4. Cytotoxicity of silver ions and AgNPs-Sericin toward VK2/E6E7 (A) and Ghost R5X4 (B) cells.

\section{In Vitro Cytotoxicity of AgNPs-Sericin}

The cytotoxicity of the AgNPs toward human ectocervix epithelial cells (VK2/E6E7) and Ghost R5X4 cells (indicator cells) was investigated. As shown in Fig. 4, the half maximal inhibitory concentration $\left(\mathrm{IC}_{50}\right)$ values of the AgNPs prepared in $0.3,3$, and $30 \mathrm{mg} / \mathrm{ml}$ sericin solution against VK2 cells were $0.33,0.31$, and $0.41 \mathrm{mM}$, respectively. Similarly, the $\mathrm{IC}_{50}$ values of these nanoparticles against Ghost cells were $0.29 \mathrm{mM}(0.3 \mathrm{mg} / \mathrm{ml}), 0.28 \mathrm{mM}(3 \mathrm{mg} / \mathrm{ml})$, and $0.46 \mathrm{mM}$ $(30 \mathrm{mg} / \mathrm{ml})$. It was indicated that the cytotoxicities of the AgNPs prepared in 0.3 and $3 \mathrm{mg} / 1$ sericin solutions were similar, but a little more toxic than AgNPs prepared in $30 \mathrm{mg} / \mathrm{ml}$ sericin. Generated Ag-NPs with higher concentrations of sericin had a larger size and high sericin content. To some extent, it may decrease the cytotoxicity of AgNPs. We also compared these nanoparticles with free silver ions, which are used as a conventional disinfectant. The result was that the $\mathrm{IC}_{50}$ of the nanoparticles was much higher than $\mathrm{AgNO}_{3}$, showing that appropriate dosages of AgNPs-Sericin were safe for microbicide use.

\section{In Vitro Anti-HIV-1 Activity of AgNPs-Sericin}

We also investigated the antiviral activity of AgNPsSericin via the HIV-1 luciferase reporter-based pseudovirus system. As shown in Fig. 5, the anti-HIV-1 activity of AgNPs-Sericin synthesized from $0.3 \mathrm{gm} / \mathrm{ml}$ sericin solution was evaluated representatively. JR-FL (CCR5-tropic strain) and HxB2 (CXCR4-tropic strain) were used, which are two American laboratory-adapted HIV strains and employ the CCR5 and CXCR4 coreceptor on the surface of the cell membrane for entry into cells, respectively. The half maximal effective concentration $\left(\mathrm{EC}_{50}\right)$ toward JR-FL and HxB2 was 47.9 and $55.6 \mu \mathrm{M}$, respectively, which was lower than the concentrations showing obvious cytotoxicity to VK2 cells and Ghost R5X4 cells. The AgNPs generated from 3 or $30 \mathrm{mg} / \mathrm{ml}$ sericin solutions showed less antiviral activity, with $\mathrm{EC}_{50}$ values greater than $100 \mu \mathrm{M}$ (data not shown). It was demonstrated that AgNPs-Sericin generated from $0.3 \mathrm{mg} / \mathrm{ml}$ sericin solution could be a potent antiviral agent against HIV-1 infection.

\section{In Vitro Antibacterial Activity of AgNPs-Sericin}

We also studied the antibacterial activity of AgNPs-Sericin prepared from $0.3 \mathrm{mg} / \mathrm{ml}$ sericin solution. The absolute bacterial cell count was evaluated via the flow cytometric method. As shown in Figs. 6A and 6B, AgNPs-Sericin exhibited potent antibacterial activities against grampositive and gram-negative bacteria in a dose-dependent

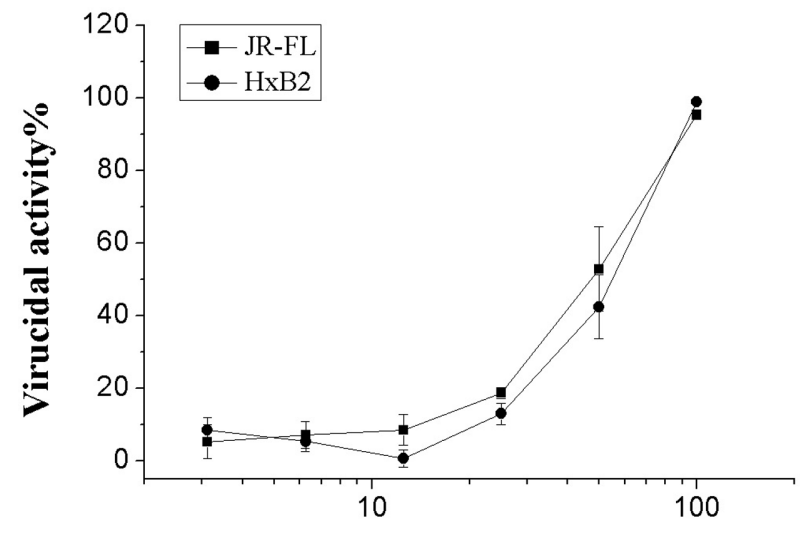

Concentration of silver nanoparticles $(\mu \mathrm{M})$

Fig. 5. Virucidal activity of AgNPs-Sericin synthesized in $0.3 \mathrm{mg} / \mathrm{ml}$ sericin solution against HIV-1 (JR-FL and HxB2 strains). 
manner. The $\mathrm{EC}_{50}$ values against $S$. aureus and E. coli were $29.82 \pm 3.82$ and $9.74 \pm 1.24 \mu \mathrm{M}$, respectively, which showed that AgNPs-Sericin was more potent for the gram-negative strain.

Whether AgNPs could cause bacterial cell damage directly was also investigated. SYBR Green/PI double fluorescent staining was employed to evaluate the cell membrane integrity after exposure to the AgNPs. We found that AgNPs-Sericin could directly destroy E. coli cell membrane integrity, but had no influence on S.aureus (Fig. 7). We concluded that AgNPs-Sericin would inhibit S. aureus cell growth through another mechanism, but not direct cell damage.

\section{Discussion}

Nowadays, bacterial and viral sexually transmitted infections have become one of the major threats to human public health, and researchers are devoting themselves to screening novel potent antimicrobial agents to prevent them. Owing to their potential properties of bioactivities, biocompatibility, and bioavailability, nanomaterials are widely applied as medicines or drug carriers for infectious disease or bacteria/virus spread control [23-25]. In the present study, we designed to prepare novel sericinconjugated AgNPs and evaluate their anti-HIV-1 and antibacterial activities. Sericin is a protein created by
A
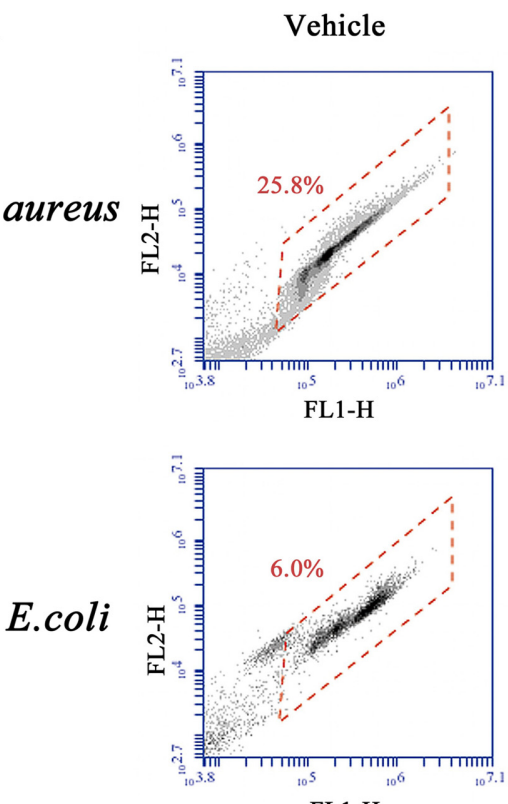

FL1-H
AgNPs-Sericin $12.5 \mu \mathrm{M}$
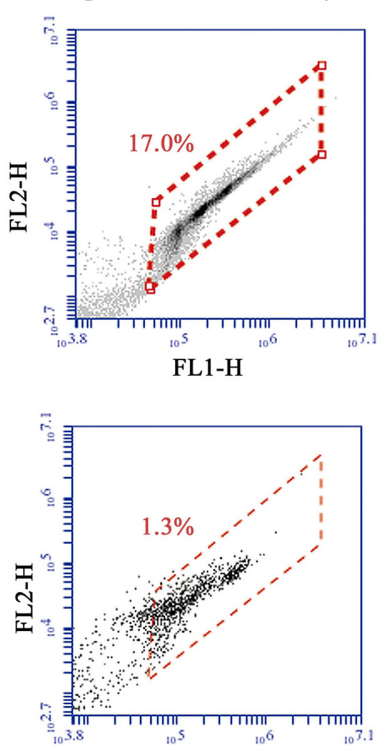

FL1-H
AgNPs-Sericin 50 $\mu \mathrm{M}$
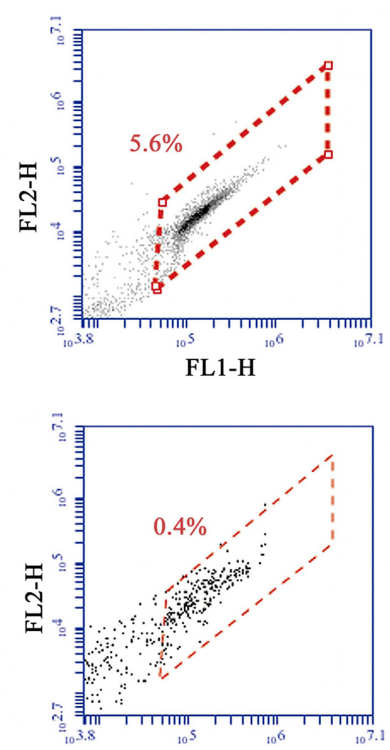

FL1-H

\section{AgNPs-Sericin $0.2 \mathrm{mM}$}
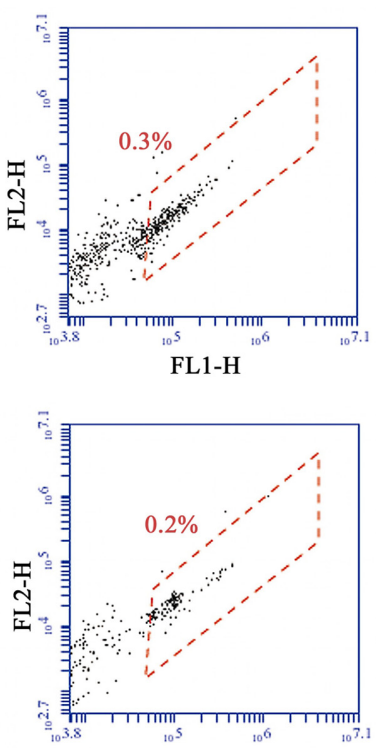

FL1-H

B
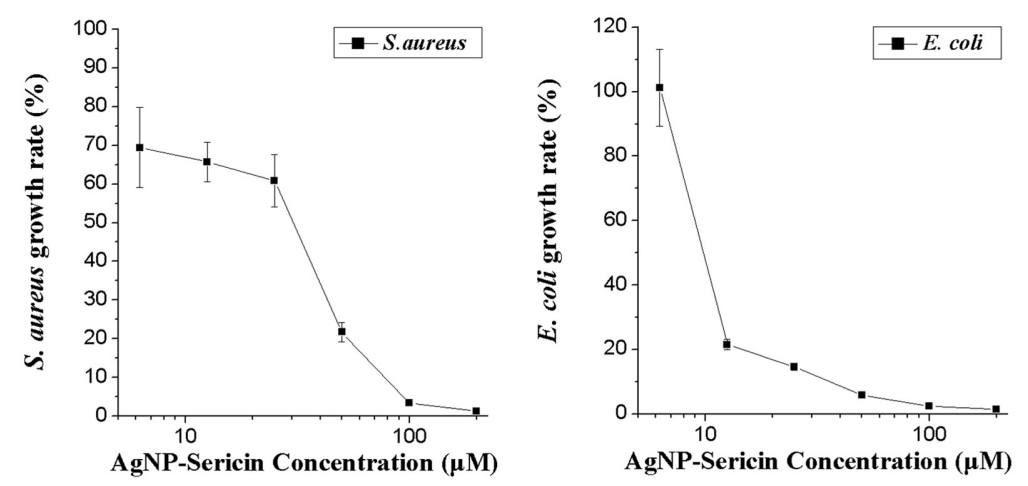

Fig. 6. Antimicrobial activity of AgNPs-Sericin synthesized in $0.3 \mathrm{mg} / \mathrm{ml}$ sericin solution against S. aureus and E. coli.

(A) Flow cytometric density plots of red (FL3) versus green (FL1) show live bacterial cell counts and density. (B) Inhibitory curves of AgNPsSericin against $S$. aureus and E. coli. 


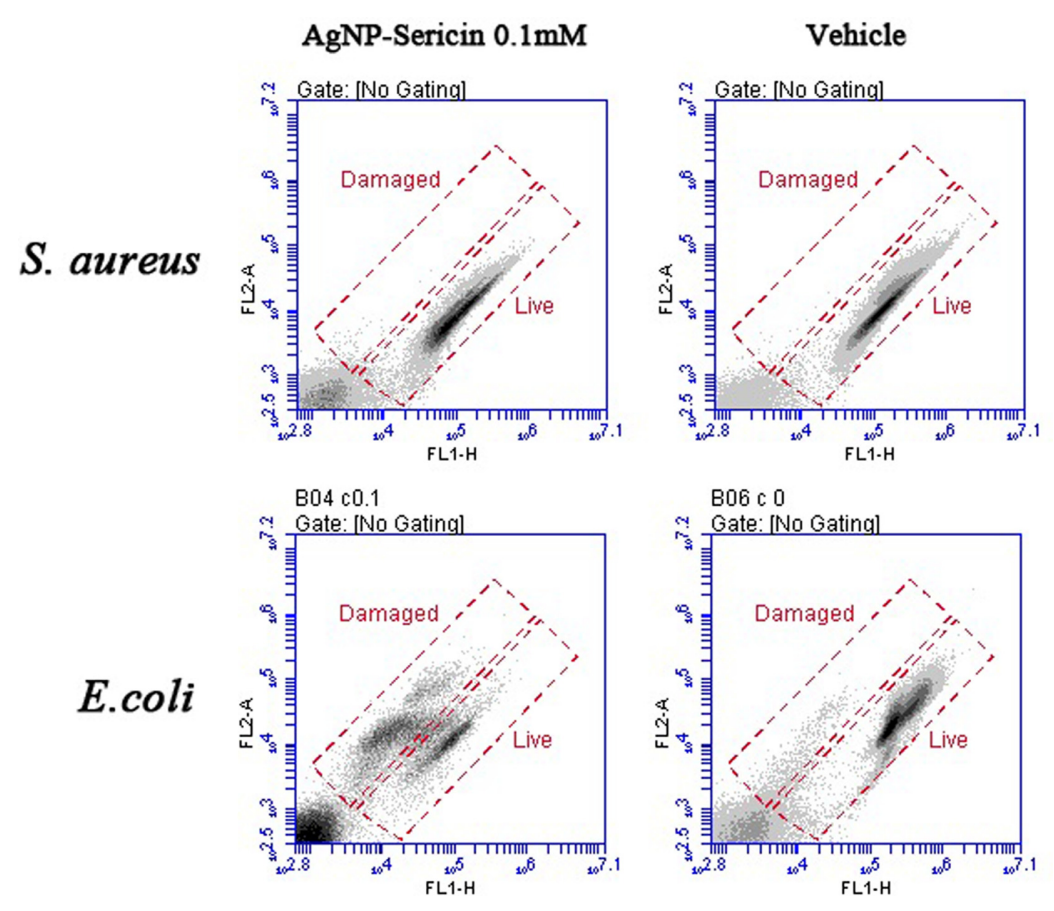

Fig. 7. Bactericidal activity of AgNPs-Sericin ( $0.1 \mathrm{mM})$ synthesized in $0.3 \mathrm{mg} / \mathrm{ml}$ sericin solution against S. aureus and E. coli.

silkworms and composed structurally of 18 different amino acids, and 32\% serine. Therefore, sericin has good hydrophilicity and reaction activity. It was found that sericin can be an excellent dispersant and modifier to control the AgNP size and shape formation. Through UVVis spectra and TEM analysis, we determined that the optimal concentration of sericin for the best dispersion effect was $0.3 \mathrm{mg} / \mathrm{ml}$. In this system, sericin is a kind of surfactant because of hydrophilic and hydrophobic aspects of its molecule. However, higher concentrations of sericin will cause larger nanoparticle sizes. We concluded that much sericin will cover the nanoparticles to cause them to aggregate owing to protein molecular charge adsorption. FTIR and TG results revealed that the AgNPs contain a certain amount of sericin. It was concluded that the existence of sericin will increase the stability of the nanoparticles, and these sericin-conjugated AgNPs may be safer than "naked" ones.

Furthermore, the anti-HIV-1 and antibacterial activities of AgNPs-Sericin were investigated. Under non-cytotoxicity concentrations, AgNPs-Sericin could exhibit significant anti-HIV-1 activity against JR-FL and HxB2 strains, indicating this kind of AgNP exhibited broad-spectrum inhibitory effects on CCR5-tropic (R5) and CXCR4-tropic viruses. It was concluded that AgNPs-Sericin could be a potential novel tropical microbicide or virucide to prevent
HIV-1 infection. The mechanism of the AgNPs against HIV-1 is not known clearly. Elechiguerra et al. [16] reported that AgNPs could interact with HIV-1 envelope glycoprotein, gp120, which was vital to process viral entry. Baram-Pinto et al. [17] also showed that AgNPs could prevent gp120 binding to CD4, the cellular receptor for HIV-1 virion entry [17]. They also demonstrated that AgNPs inhibit post-entry stages of the HIV-1 life cycle, implying that they might influence certain viral enzymes or functional proteins activity [17]. The multi-targets of AgNPs against HIV-1 and their antiviral mechanisms should be further investigated.

After that, the antibacterial activity of AgNPs-Sericin was also studied via the flow cytometry approach. Compared with traditional CFU counting or the spectrophotometer method, flow cytometry measurement has been proven to be a rapid, accurate, and automatic detection of bacterial counts [22]. The results showed that AgNPs-Sericin was more potent for gram-negative than gram-positive bacteria (Figs. 6 and 7). We concluded that the different inhibitory efficiency might be related to the composition differences of the gram-negative and gram-positive bacteria cell walls, and the AgNPs could penetrate gram-negative bacteria cells more easily than gram-positive ones. The study of the exact antibacterial mechanism is still under way.

AgNPs have been applied widely in healthcare and medicine, and the antimicrobial and antiviral activities 
have been confirmed in our manuscript. It has been employed as a component of the coating of condom and other products. We have provided a novel method to prepare AgNPs to be used as a potential tropic microbicide or an antimicrobial agent that is low-cost and efficient.

\section{Acknowledgments}

This project was supported by the Foundation of the Science and Technology Development Project of Nanjing Medical University (2015NJMU175); Foundation of the Science and Technology Project of Wujin (WS201402); Foundation of the Youth Science and Technology Project of Changzhou Health and Family Planning Commission (QN201505); Innovative and Entrepreneurial Plan of Jiangsu Province; and Changzhou High-Level Medical Talents Training Project (No: 2016CZBJ060).

\section{Conflict of Interest}

The authors have no financial conflicts of interest to declare.

\section{References}

1. Alanis AJ. 2005. Resistance to antibiotics: are we in the postantibiotic era? Arch. Med. Res. 36: 697-705.

2. Fauci AS. 1999. The AIDS epidemic - considerations for the 21st century. N. Engl. J. Med. 341: 1046-1050.

3. Kahn JO, Walker BD. 1998. Acute human immunodeficiency virus type 1 infection. N. Engl. J. Med. 339: 33-39.

4. Stone A. 2002. Microbicides: a new approach to preventing HIV and other sexually transmitted infections. Nat. Rev. Drug Discov. 1: 977-985.

5. Balzarini J, Van Damme L. 2007. Microbicide drug candidates to prevent HIV infection. Lancet 369: 787-797.

6. Neu HC. 1992. The crisis in antibiotic resistance. Science 257: 1064-1073.

7. Bönnemann H, Richards RM. 2001. Nanoscopic metal particles - synthetic methods and potential applications. Eur. J. Inorg. Chem. 2001: 2455-2480.

8. Hirsch LR, Stafford R, Bankson J, Sershen S, Rivera B, Price R, et al. 2003. Nanoshell-mediated near-infrared thermal therapy of tumors under magnetic resonance guidance. Proc. Natl. Acad. Sci. USA 100: 13549-13554.

9. Liau S, Read D, Pugh W, Furr J, Russell A. 1997. Interaction of silver nitrate with readily identifiable groups: relationship to the antibacterial action of silver ions. Lett. Appl. Microbiol. 25: 279-283.

10. Nomiya K, Yoshizawa A, Tsukagoshi K, Kasuga NC, Hirakawa S, Watanabe J. 2004. Synthesis and structural characterization of silver(I), aluminium(III) and cobalt(II) complexes with 4-isopropyltropolone (hinokitiol) showing noteworthy biological activities. Action of silver(I)-oxygen bonding complexes on the antimicrobial activities. J. Inorg. Biochem. 98: 46-60.

11. Gupta A, Silver S. 1998. Molecular genetics: silver as a biocide: will resistance become a problem? Nat. Biotechnol. 16: 888 .

12. Fedlheim DL, Foss CA. 2001. Metal Nanoparticles: Synthesis, Characterization, and Applications. CRC Press, Boca Raton, FL.

13. Lok C-N, Ho C-M, Chen R, He Q-Y, Yu W-Y, Sun H, et al. 2006. Proteomic analysis of the mode of antibacterial action of silver nanoparticles. J. Proteome Res. 5: 916-924.

14. Das R, Gang S, Nath SS. 2011. Preparation and antibacterial activity of silver nanoparticles. J. Biomater. Nanobiotechnol. 2: $472-475$.

15. Li C, Wang X, Chen F, Zhang C, Zhi X, Wang K, et al. 2013. The antifungal activity of graphene oxide-silver nanocomposites. Biomaterials 34: 3882-3890.

16. Elechiguerra JL, Burt JL, Morones JR, Camacho-Bragado A, Gao X, Lara $\mathrm{HH}$, et al. 2005. Interaction of silver nanoparticles with HIV-1. J. Nanobiotechnol. 3: 1-10.

17. Baram-Pinto D, Shukla S, Perkas N, Gedanken A, Sarid R. 2009. Inhibition of herpes simplex virus type 1 infection by silver nanoparticles capped with mercaptoethane sulfonate. Bioconjug. Chem. 20: 1497-1502.

18. AshaRani P, Low Kah Mun G, Hande MP, Valiyaveettil S. 2008. Cytotoxicity and genotoxicity of silver nanoparticles in human cells. ACS Nano 3: 279-290.

19. Zhang YQ. 2002. Applications of natural silk protein sericin in biomaterials. Biotechnol. Adv. 20: 91-100.

20. Li M, Gao F, Mascola JR, Stamatatos L, Polonis VR, Koutsoukos M, et al. 2005. Human immunodeficiency virus type $1 \mathrm{env}$ clones from acute and early subtype B infections for standardized assessments of vaccine-elicited neutralizing antibodies. J. Virol. 79: 10108-10125.

21. Johnson V, Byington R, Aldovani A, Walker B. 1990. Infectivity assay (virus yield assay), pp. 71-76. In Aldovani $\mathrm{A}$ and Walker BD (eds.), Techniques in HIV research. Stockton Press, New York, NY.

22. Pan H, Zhang Y, He G-X, Katagori N, Chen H. 2014. A comparison of conventional methods for the quantification of bacterial cells after exposure to metal oxide nanoparticles. BMC Microbiol. 14: 222.

23. Morones JR, Elechiguerra JL, Camacho A, Holt K, Kouri JB, Ramírez JT, et al. 2005. The bactericidal effect of silver nanoparticles. Nanotechnology 16: 2346-2353.

24. Ravichandran R. 2009. Nanotechnology-based drug delivery systems. Nanobiotechnology 5: 17-33.

25. Galdiero S, Falanga A, Vitiello M, Cantisani M, Marra V, Galdiero M. 2011. Silver nanoparticles as potential antiviral agents. Molecules 16: 8894-8918. 